\title{
Deformation-Induced Large Ductility of Super Saturated Solid Solution Fe-Cu Alloy
}

\author{
Licai Fu* , Jun Yang, Qinling Bi, Weimin Liu
}

State Key Laboratory of Solid Lubrication, Lanzhou Institute of Chemical Physics, Chinese Academy of Sciences, Lanzhou, China. Email: *licaifu@licp.cas.cn

Received September $25^{\text {th }}, 2011$; revised October $29^{\text {th }}, 2011$; accepted November $7^{\text {th }}, 2011$.

\begin{abstract}
The mechanical properties of super saturated solid solution $\mathrm{Fe}_{60} \mathrm{Cu}_{40}$ alloy has been investigated using compression test. The results show that the grain precipitation and phase transformation occurs during compressive deformation resulting in large work-hardening ability, high strength and large ductility. Our results demonstrate that this novel architecture offers a design pathway towards a new generation of strong materials with large ductility.
\end{abstract}

Keywords: Fe-Cu Alloy, Super Solid Solution, Precipitation, Phase Transform, Ductility

\section{Introduction}

Strength and ductility are of the most important mechanical properties of structural materials. However, they are often difficult to obtain the high strong and large ductility simultaneously $[1,2]$. Generally, the low ductility of materials is attributed to the lack of work hardening caused by their inability to accumulate dislocations [3]. Therefore, the basic idea to improve the ductility of materials is to regain the work hardening (dislocation accumulation capability), which is often accompanied with sacrifice of strength. Classical methods for strengthening materials contain solid solution, dislocation, grain boundary and so on [4]. The solid solution strength metals are to alloy them with elements that are dissolved in the crystal lattice and form a solid solution. Such atoms elastically distort the crystal and can thus interact with the stress field of a dislocation and impede its movement, which results in high strength [5]. On the other hand, large numbers of reports indicated precipitate and phase transformation are also beneficial to improve the ductility during deformation of alloys. Kim showed that certain size of precipitate can improve the hardness and work hardening of the materials [6]. Their excellent mechanical properties result from the martensitic transformation of metastable retained austenite, induced by thermomechanical loading $[7,8]$.

Dendrite composite immiscible $\mathrm{Fe}_{60} \mathrm{Cu}_{40}$ alloy has been prepared successfully by combustion synthesis technique (CS) [9]. By controlling the applied pressure, the different super saturated solid solution $\mathrm{Fe}_{60} \mathrm{Cu}_{40}$ alloys have been obtained. Especially, there are not large composite segregation both in dendrite and matrix. In this paper, we examined the mechanical properties of this special alloy under compression test. The results show that the nanoscale precipitation and phase transformation occurs during compressive deformation resulting in large work- hardening ability and high strength. Our results demonstrate that this novel architecture offers a design pathway towards both strong and ductility materials.

\section{Experimental}

The $\mathrm{Fe}_{60} \mathrm{Cu}_{40}$ alloy has been prepared successfully by CS [9]. In this paper, the $\mathrm{Fe}_{60} \mathrm{Cu}_{40}$ alloys with different microstructure have been produced by CS under different applied pressure with 8, 6 and $4 \mathrm{MPa}$ of argon gas, which indicated as $\mathrm{FC}_{8}, \mathrm{FC}_{6}$ and $\mathrm{FC}_{4}$, respectively. Morphologies and compositions of the $\mathrm{Fe}_{60} \mathrm{Cu}_{40}$ alloys were examined using a JSM-5600LV scanning electron microscope (SEM) equipped with an energy dispersive X-ray spectroscope (EDS, Kevex, USA). Cylindrical compressive specimens with length of $4.5 \mathrm{~mm}$ and a diameter of 2.8 $\mathrm{mm}$ were cut using an electro-discharging machine, and both ends of the compressive specimens were polished to mirror surfaces, and coated with graphite before tests to reduce the interfacial friction. Quai-static uniaxial compression test were performed at room temperature using a testing machine with a crosshead speed of $3.5 \times 10^{-3} \mathrm{~s}^{-1}$. The before and after compression test samples were in- 
vestigated with X-ray diffractometry (XRD, Philips X'pert) using $\mathrm{CuK} \alpha$ radiation. The cross sections of fractured $\mathrm{Fe}_{60} \mathrm{Cu}_{40}$ alloys were also analyzed by the SEM.

\section{Results}

The typical compressive engineering stress-strain curves of the $\mathrm{Fe}_{60} \mathrm{Cu}_{40}$ alloys are compared in Figure 1. The yield strength $\sigma_{y}$, ultimate fracture strength $\sigma_{\max }$, fractural strain $\varepsilon_{f}$ are also given in table inset of Figure 1. The yield strengths of the $\mathrm{FC}_{8}, \mathrm{FC}_{6}$, and $\mathrm{FC}_{4}$ samples are 520 $\mathrm{MPa}, 900 \mathrm{MPa}$, and $790 \mathrm{MPa}$, respectively, which are higher than that of commercial crystalline $\mathrm{Cu}-\mathrm{Fe}$ alloys [10]. The highest yield strength is obtained with applied pressure $6 \mathrm{MPa}$. As shown, the uniform elongation of the $\mathrm{FC}_{8}$ and $\mathrm{FC}_{4}$ are only $4 \%$ to $5 \%$. In contrast, the uniform elongation of the $\mathrm{FC}_{6}$ reaches about $20 \%$. It is more than fourfold that of the nanostructured sample and above the critical ductility required for many structural applications. The ductility of the $\mathrm{FC}_{6}$ enhances because of an improved work-hardening rate. The strong working hardening allows uniform deformation, and leads to a fast climbing curve in the compression test, which is different with most nanostructured metals and alloys that show plunging curves peaking very early in plastic deformation [1]. So, the strain to failure reaches $30 \%$ in the compression.

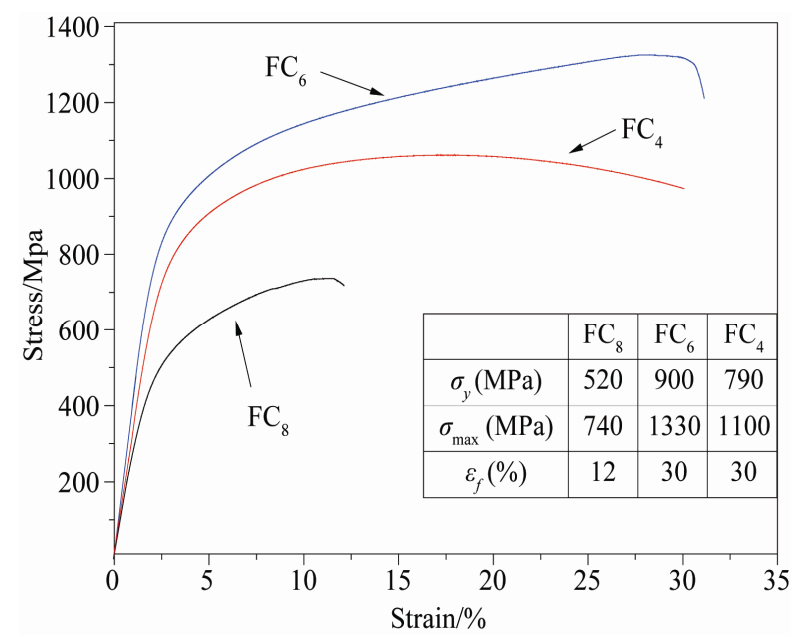

Figure 1. Compressive engineering stress-strain cures of the $\mathrm{Fe}_{60} \mathrm{Cu}_{40}$ alloy. Table of inset is the yield strength $\sigma_{\mathrm{y}}$, ultimate fracture strength $\sigma_{\max }$, fractured strain $\varepsilon_{f}$ of the $\mathrm{Fe}_{60} \mathrm{Cu}_{40}$ alloys.

Table 1. Composition of the $\mathrm{Fe}_{60} \mathrm{Cu}_{40}$ alloys.

\begin{tabular}{ccccccc}
\hline & \multicolumn{2}{c}{$\mathrm{FC}_{8}$} & \multicolumn{2}{c}{$\mathrm{FC}_{6}$} & \multicolumn{2}{c}{$\mathrm{FC}_{4}$} \\
\cline { 2 - 7 } & dendrite & matrix & dendrite & matrix & dendrite & matrix \\
\hline $\mathrm{Cu}$ & 15.4 & 75.5 & 16.1 & 64.4 & 20.0 & 56.6 \\
$\mathrm{Fe}$ & 84.6 & 24.5 & 83.9 & 35.6 & 80.0 & 43.4 \\
\hline
\end{tabular}

The SEM secondary electron images of the $\mathrm{FC}_{8}$ and $\mathrm{FC}_{6}$ and $\mathrm{FC}_{4}$ are shown in Figure 2. All of the dendrites of the $\mathrm{FeCu}$ alloys are uniformly embedded into the matrix. It is maybe brought from the polishing because of the soft matrix ( $\mathrm{Cu}$ solid solution). The matrix is composed of equiaxed ultrafine grains [9]. For $\mathrm{FC}_{8}$ the primary dendrite axes have radii of about $2-5 \mu \mathrm{m}$, regular patterns of secondary dendrite arms with spacing $1-3$ $\mu \mathrm{m}$ are observe, having radii of about $2 \mu \mathrm{m}$, which is smaller than the primary axis (Figure 2(a)). The primary and second dendrite axes become short and coarse as the applied pressure decreases (Figure 2(b)). The primary dendrite axes break and second dendrite axes get to rarely when the applied pressure decreases to the $4 \mathrm{MPa}$ (Figure 2(c)). The composite of the dendrite and matrix are presented in Table 1. The results shows that the dendrite and matrix are $\mathrm{Fe}(\mathrm{Cu})$ solid solution and $\mathrm{Cu}(\mathrm{Fe})$ solid solution, respectively, for all the $\mathrm{FeCu}$ alloys. It should be noted that all the $\mathrm{FeCu}$ alloys are only, composed of elements $\mathrm{Fe}$ and $\mathrm{Cu}$. It confirms the small black holes in the matrix are not impurity (Figure 2). The dendrite and matrix are $\mathrm{Fe}(\mathrm{Cu})$ solid solution $(15.4 \mathrm{at} \% \mathrm{Cu})$ and $\mathrm{Cu}(\mathrm{Fe})$ solid solution $(24.5 \mathrm{at} \% \mathrm{Fe})$, respectively, for the $\mathrm{FC}_{8}$. However, the solid solubility of the $\mathrm{Fe}(\mathrm{Cu})$ and $\mathrm{Cu}(\mathrm{Fe})$ increases to the 20 at $\%$ and 43.4 at $\%$, respectively for the $\mathrm{FC}_{4}$. It means that both solid solubility of the $\mathrm{Fe}(\mathrm{Cu})$ and $\mathrm{Cu}(\mathrm{Fe})$ increase as the applied pressure decreases. Impressively, the solid solubility of the $\mathrm{Cu}(\mathrm{Fe})$ with applied $4 \mathrm{MPa}$ is twice as with applied $8 \mathrm{MPa}$.
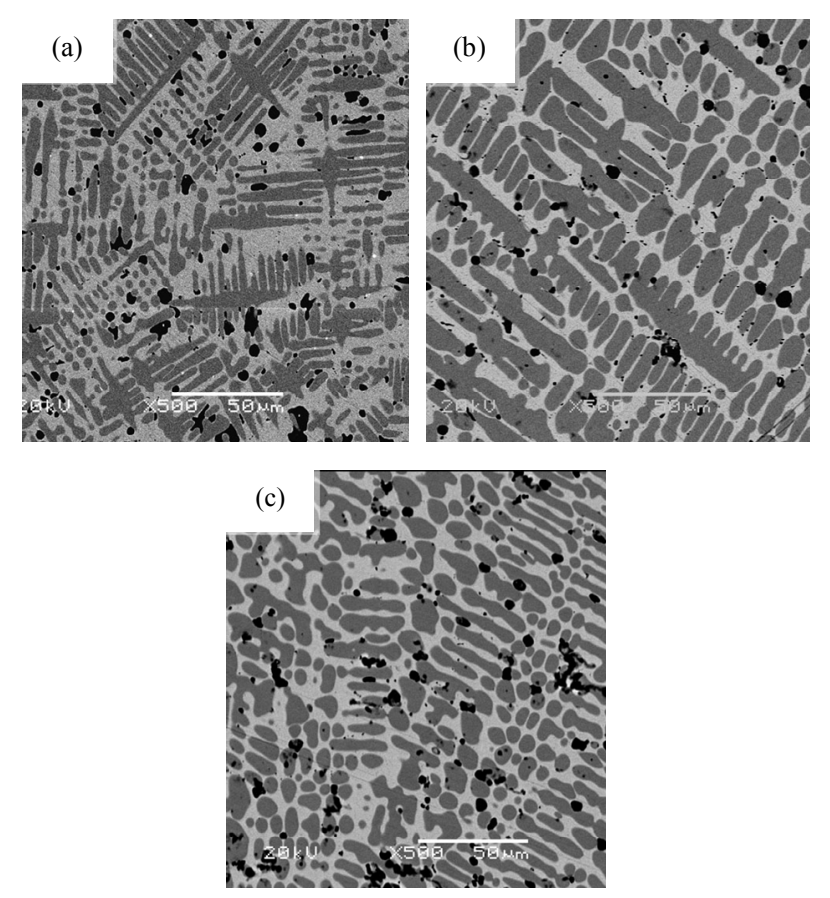

Figure 2. SEM images of the $\mathrm{Fe}_{60} \mathrm{Cu}_{40}$ alloys, (a) $8 \mathrm{MPa}$, (b) $6 \mathrm{MPa},(\mathrm{c}) 4 \mathrm{MPa}$. 
Figure 3 shows the XRD pattern of $\mathrm{Fe}_{60} \mathrm{Cu}_{40}$ alloys before and after compressive deformation. All the $\mathrm{FC}_{8}$, $\mathrm{FC}_{6}$, and $\mathrm{FC}_{4}$ before and after compressive deformation contain the $\varepsilon$-Cu-rich and the $\alpha$-Fe-rich phases. The diffraction peak $\gamma$-Fe-rich phase changes weak as the applied pressure decreases, and the $\gamma$-Fe-rich phase has not been examined using XRD when the applied pressure decreases to $4 \mathrm{MPa}$. However, the $\gamma$-Fe structure occurs after $\mathrm{FC}_{4}$ deformation. Another impressively characterization is that the diffraction peaks of the $\varepsilon$-Cu-rich structure shift towards higher angles and $\gamma$-Fe-rich towards lower angle after $\mathrm{Fe}_{60} \mathrm{Cu}_{40}$ alloys deformation. It means that the solid solution of the $\varepsilon$-Cu-rich and $\gamma$-Fe-rich in $\mathrm{Fe}_{60} \mathrm{Cu}_{40}$ alloys decreases after the compressive deformation. It is to be noted that $\mathrm{FC}_{6}$ has the highest ratio of $\varepsilon$-Cu-rich to $\gamma$-Fe-rich (defined as ratio of diffraction peaks).

The fractography of the $\mathrm{Fe}_{60} \mathrm{Cu}_{40}$ alloys is shown in Figure 4. The intergranular fracture feature has been observed in the fractured surface of the $\mathrm{FC}_{6}$ (Figure 4(a)). The crack occurs along the dendrite axis because of the stress concentration in soft matrix in the compressive deformation. Some of the dendrite axis cracked when the stress concentration increases to the critical value, such as the zone of III. The Figure 4(b), (c) and (d) are magnification of the I, II and III of the Figure 4(a), respectively. Far from the fractured dendrite axis, large numbers of small grains precipitate from the dendrite and matrix (Figure 4(b)). Near the fractured dendrite axis ( II), more precipitations occur, and lots of dimples has been observed with grain size of ultrafine scale comparing with the precipitation. The visible melt traces (Figure 4(d)) are regarded as matrix (melt pointing is about $1000^{\circ} \mathrm{C}$ ) because the local temperature maybe is higher $1000^{\circ} \mathrm{C}$ the local stress concentration as the sample fractures. The

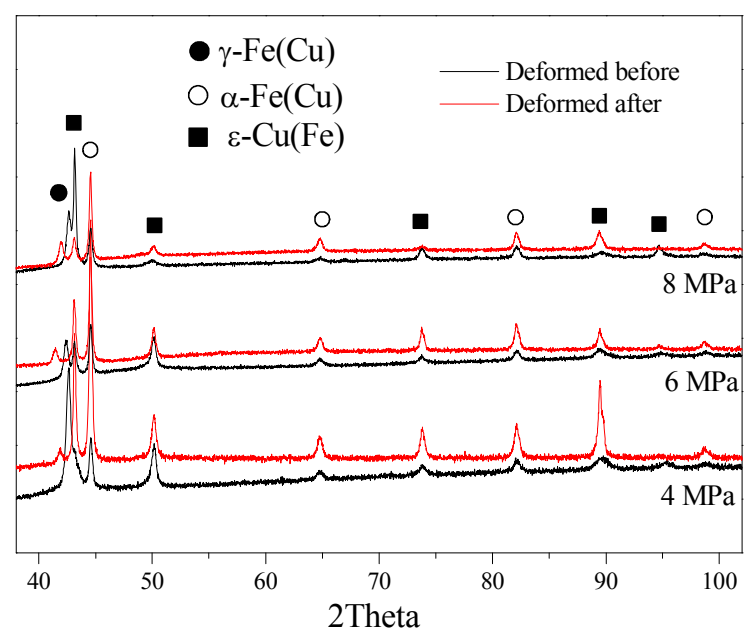

Figure 3. XRD patterns of the deformed before and after $\mathrm{Fe}_{60} \mathrm{Cu}_{40}$ alloys.
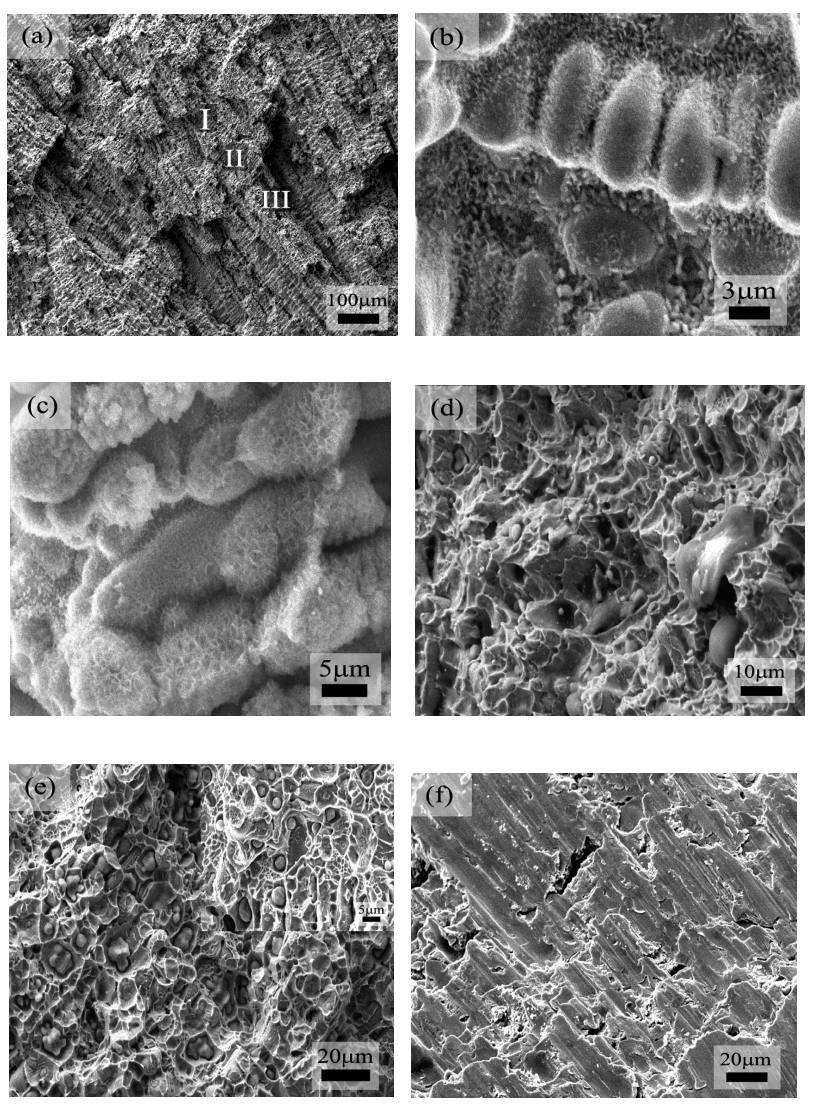

Figure 4. Fractography of the $\mathrm{Fe}_{60} \mathrm{Cu}_{40}$ alloys (a), (b), (c), (d) $\mathrm{FC}_{6}$; (e) $\mathrm{FC}_{4}$; (f) $\mathrm{FC}_{8}$.

dimples indicate good working har- den of the $\mathrm{FC}_{6}$. The super saturated solid solution of the $\mathrm{FC}_{4}$ with $\mathrm{Cu}(\mathrm{Fe})$ and $\mathrm{Fe}(\mathrm{Cu})$ is close to the $\mathrm{FC}_{6}$. Thus, the yield strength reaches $790 \mathrm{MPa}$, is near the yield strength of the $\mathrm{FC}_{6}(900$ $\mathrm{MPa}$ ). However, the local stress concentration of the $\mathrm{FC}_{4}$ is smaller than that of the $\mathrm{FC}_{6}$, because the dendrite axis of the $\mathrm{FC}_{4}$ is coarse and short compared with the $\mathrm{FC}_{6}$. So, the working harden is decreases even the negative value. For the $\mathrm{FC}_{8}$, owing to the smaller dendrite axis and smaller solid solution, the strength and ductility are smaller than that of the $\mathrm{FC}_{6}$.

\section{Conclusions}

In this paper, the bulk immiscible $\mathrm{Fe}_{60} \mathrm{Cu}_{40}$ alloy is successfully prepared by a combustion synthesis technique. The $\mathrm{Fe}_{60} \mathrm{Cu}_{40}$ alloy is composed of Fe-rich dendritic embedded in Cu-rich matrix uniformly. The content of the dendrite and matrix are $34.5 \%$ and $65.5 \%$, respectively. The grain size of matrix is about $30 \mathrm{~nm}$. Owing to the very high superheating $\left(4700^{\circ} \mathrm{C}\right)$ of combustion synthesis, the deeply undercooling is obtained, resulting there no large-scaled phase separation into $\mathrm{Cu}$-rich and Fe-rich phases. 


\section{REFERENCES}

[1] M. A. Meyers, A. Mishra and D. J. Benson, "Mechanical Properties of Nanocrystalline Materials," Progress in Materials Science, Vol. 51, No. 4, 2006, pp. 427-556. doi:10.1016/j.pmatsci.2005.08.003

[2] C. C. Koch, I. A. Ovid'ko, S. Seal and S. Veprek, "Structural Nanocrystalline Materials: Fundamentals and Applications," Cambridge University Press, Cambridge, 2007. doi:10.1017/CBO9780511618840

[3] L. Capolungo, D. E. Spearot, M. Cherkaoui, D. L. McDowell, J. Qu and K. I. Jacob, "Dislocation Nucleation from Bicrystal Interfaces and Grain Boundary Ledges: Relationship to Nanocrystalline Deformation," Journal of the Mechanics and Physics of Solids, Vol. 55, No. 11, 2007, pp. 2300-2327. doi:10.1016/j.jmps.2007.04.001

[4] K. Lu, L. Lu and S. Suresh, "Strengthening Materials by Engineering Coherent Internal Boundaries at the Nanoscale," Science, Vol. 324, No. 5925, 2009, pp. 349-352.

[5] J. Rösler, H. Harders and M. Bäker, "Mechanical Behaviour of Engineering Materials," Springer-Verlag, Berlin 2007.

[6] J. Kim, M. Lee, D. Kim and R. Wagoner, "Micromechan-
ics-Based Strain Hardening Model in Consideration of Dislocation-Precipitate Interactions," Metals and Materials International, Vol. 17, 2011, p. 291. doi:10.1007/s12540-011-0417-4

[7] Y. Ivanisenko, I. MacLaren, X. Sauvage, R. Z. Valiev and H. Fecht, "Shear-Induced $\alpha \rightarrow \gamma$ Transformation in Nanoscale Fe-C Composite," Acta Materialia, Vol. 54, No. 6, 2006, pp. 1659-1669. doi:10.1016/j.actamat.2005.11.034

[8] C. Yoo, Y. Park, Y. Jung and Y. Lee, "Effect of Grain Size on Transformation-Induced Plasticity in an Ultrafine-Grained Metastable Austenitic Steel," Scripta Materialia, Vol. 59, No. 1, 2008, pp. 71-74. doi:10.1016/j.scriptamat.2008.02.024

[9] L. Fu, J. Yang, Q. Bi and W. Liu, "Combustion Synthesis Immiscible Nanostructured Fe-Cu Alloy," Journal of Alloys and Compounds, Vol. 482, No. 1-2, 2009, pp. L22L24. doi:10.1016/j.jallcom.2009.04.016

[10] H. Kakisawa, K. Minagawa and K. Halada, "Tensile Behavior Change Depending on the Microstructure of a $\mathrm{Fe}-\mathrm{Cu}$ Alloy Produced from Rapidly Solidified Powder," Materials Science and Engineering: A, Vol. 340, No. 1-2, 2003, pp. 175-180. doi:10.1016/S0921-5093(02)00171-5 